\title{
COMPOSTOS ORGÂNICOS VOLÁTEIS NA DEFESA INDUZIDA DAS PLANTAS CONTRA INSETOS HERBÍVOROS
}

Delia M. Pinto-Zevallos, Camila B. C. Martins, Ana C. Pellegrino e Paulo H. G. Zarbin*

Departamento de Química, Universidade Federal do Paraná, 81531-990 Curitiba - PR, Brasil

Recebido em 5/2/13; aceito em 4/7/13; publicado na web em 9/8/13

\begin{abstract}
VOLATILE ORGANIC COMPOUNDS IN INDUCED PLANT DEFENSE AGAINST HERBIVOROUS INSECTS. The identification and manipulation of chemical compounds involved in vital activities of arthropods have the potential for developing less aggressive pest control strategies. Herbivory induces the emission of volatile organic compounds involved in the recruitment of natural enemies, plantplant interactions and repellency of other herbivores. In this report, we review the main chemical groups of volatile organic compounds and their ecological functions, provide an overview of the signal transduction pathways activated upon herbivory, and review the current state of knowledge for practical applications in pest management. We conclude by proposing perspectives for future research.
\end{abstract}

Keywords: plant chemical defenses; herbivore-induced plant volatile organic compounds; sustainable agriculture.

\section{INTRODUÇÃO}

Nas últimas décadas presenciamos uma constante pressão da sociedade para aumentar a sustentabilidade de atividades produtivas, o que requer a criação de inovações e tecnologias menos agressivas ao meio ambiente e à saúde humana. Neste contexto, pesquisadores dedicados ao estudo do controle de pragas agrícolas têm um grande interesse no desenvolvimento de estratégias ecológicas e sustentáveis para programas de manejo integrado de pragas (MIP).

$\mathrm{Na}$ natureza, as plantas desenvolveram e aperfeiçoaram uma diversidade considerável de mecanismos de defesa contra condições ambientais adversas, tais como o ataque de macro- e microorganismos antagonistas. São exemplos de defesa contra artrópodes herbívoros a produção de metabólitos secundários tóxicos (aleloquímicos), como a nicotina ou furanocumarinas, que podem matar herbívoros generalistas não adaptados, e proteínas de defesa, como inibidores de proteases ou polifenol oxidases, que dificultam a digestão e diminuem a disponibilidade de nutrientes e, consequentemente, o crescimento dos herbívoros. ${ }^{1}$ Esses mecanismos são considerados defesas diretas, uma vez que afetam diretamente os herbívoros ao impedir que estes se alimentem. Outros tipos de defesa direta das plantas são as barreiras físicas que impedem a entrada de patógenos ou artrópodes nos tecidos, ou seja, a parede celular, suberina, calose e cutícula. ${ }^{2}$ Além das defesas diretas, a presença de estruturas que oferecem proteção e alimento, tais como domatias e nectários extraflorais promovem a defesa indireta através da atração de parasitoides e predadores que exercem controle biológico sobre os herbívoros. ${ }^{1}$

As defesas das plantas não são somente expressadas constitutivamente, elas também podem ser induzidas em resposta ao stress abiótico ou biótico, como por exemplo, à herbivoria. ${ }^{3}$ Estas defesas induzidas oferecem muitas vantagens para a planta, uma vez que reduzem o investimento em mecanismos de defesa, retardam a adaptação e o desenvolvimento de resistência dos herbívoros. ${ }^{4}$ No caso das defesas indiretas, a mudança no volume e concentração de açúcares e aminoácidos do néctar extrafloral, ${ }^{5}$ assim como a produção e emissão de compostos orgânicos voláteis ${ }^{6}$ promove a atração de predadores (principalmente formigas no caso do néctar extrafloral) e parasitoides no caso de respostas frente à herbivoria.

*e-mail: pzarbin@ufpr.br
Os voláteis induzidos após o ataque dos herbívoros têm despertado o interesse na comunidade científica, uma vez que eles não só guiam os inimigos naturais em direção à planta hospedeira da presa, mas também na mediação de várias interações ecológicas que têm potencial para o desenvolvimento de novas estratégias de controle de pragas. ${ }^{7}$ A Ecologia Química, ciência que estuda os compostos químicos envolvidos nas interações entre organismos vivos (moléculas "sinais" conhecidas como semioquímicos), tem permitido a ampliação do conhecimento no papel dos voláteis ao combinar áreas como a Química, a Entomologia, a Botânica, a Biologia Molecular, dentre outras. Esta revisão visa resumir o conhecimento atual sobre as funções ecológicas, biossíntese e vias metabólicas de indução de voláteis, além de discutir a importância desses compostos químicos visando o controle de pragas, destacando o conhecimento atual e identificando a necessidade de pesquisas futuras.

\section{FUNÇÕES E BIOSÍNTESE DOS VOLÁTEIS INDUZIDOS APÓS A HERBIVORIA}

$\mathrm{Na}$ natureza, os voláteis têm muitas funções eco-fisiológicas (Figura 1). Constitutivamente, eles oferecem à planta defesa contra agentes de stress e permitem a comunicação entre a planta e o meio ambiente. Os isoprenoides (isopreno e os terpenoides) protegem a planta contra agentes abióticos, tais como a oxidação, ao extinguir espécies de oxigênio reativas e ao reagir com o ozônio $\left(\mathrm{O}_{3}\right)$ da atmosfera. ${ }^{8}$ Além disso, protegem a planta do calor ao reduzir espécies de oxigênio reativas produzidas por altas temperaturas, ${ }^{9}$ protegem as plantas de micro-organismos ${ }^{10}$ e repelem insetos. ${ }^{11}$ Os voláteis também mediam interações entre plantas e herbívoros, as quais são importantes, já que vinculam cadeias alimentares em ecossistemas complexos. Eles mediam a atração de polinizadores às flores ${ }^{12} \mathrm{e}$ possivelmente de animais disseminadores de sementes ${ }^{13}$ assim como a localização de plantas hospedeiras por insetos herbívoros. ${ }^{14}$ Já os voláteis induzidos provocam a atração de inimigos naturais (predadores e parasitoides) tanto na parte aérea, ${ }^{15}$ como na parte subterrânea ${ }^{16}$ das plantas e estão envolvidos nas interações planta-planta. ${ }^{17}$

\section{"Pedindo ajuda": o chamado aos inimigos naturais}

Embora muitos inimigos naturais explorem compostos emitidos pela presa ou derivados desta, ${ }^{18}$ esses compostos são emitidos em 


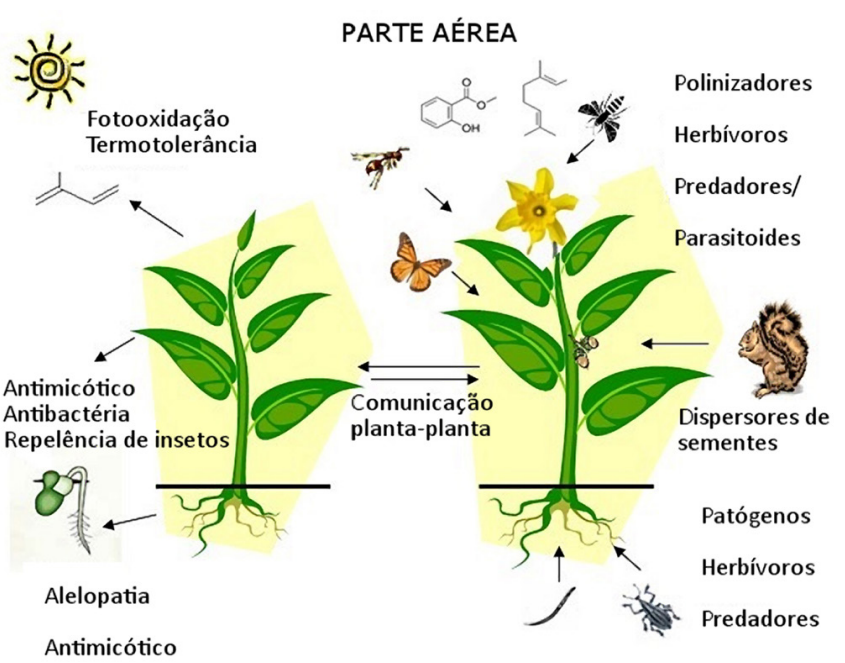

Antibactéria

\section{PARTE SUBTERRÂNEA}

Figura 1. Funções eco-fisiológicas dos voláteis emitidos constitutiva e induzidamente pelas plantas (Modificado de Dudareva ${ }^{36}$ )

quantidades muito pequenas se considerarmos a biomassa dos insetos. Além disso, os insetos herbívoros estão constantemente se adaptando para não serem detectados por seus inimigos naturais. ${ }^{19} \mathrm{~A}$ adaptação de muitos inimigos naturais aos voláteis induzidos é de grande vantagem tanto para as plantas quanto para os predadores. O papel dos voláteis induzidos após o ataque dos herbívoros nas interações tritróficas tem sido evidenciado através de estudos que avaliaram a resposta eletrofisiológica ${ }^{20}$ e comportamental ${ }^{21}$ de inimigos naturais, e estas têm sido demonstradas em muitos sistemas que incluem plantas mono- e dicotiledôneas, arbustivas e arbóreas, artrópodes mastigadores e sugadores, e artrópodes predadores e parasitoides de muitas ordens taxonômicas. ${ }^{6} \mathrm{~A}$ emissão sistêmica de voláteis em várias plantas após a oviposição de vários herbívoros tambémé capaz de atrair parasitoides de ovos. ${ }^{22} \mathrm{O}$ mesmo ocorre com os nematoides entomopatogênicos que incrementam a mortalidade dos herbívoros ${ }^{23}$ os quais são atraídos às raízes das plantas pelos voláteis induzidos como resposta a herbívoros que se desenvolvem na parte subterrânea. ${ }^{16}$

Os voláteis induzidos após o ataque dos herbívoros apresentam grande variabilidade e dependem da espécie de planta, ${ }^{24}$ do herbívoro ${ }^{25}$ e do seu instar ou estadio. ${ }^{26}$ Também variam com o genótipo ${ }^{27}$ e, neste caso, entre partes da planta e de acordo com o tempo, ${ }^{28}$ considerado pelo período de 24 horas, uma vez que as emissões destes variam de dia e noite..$^{29}$ Isto facilita a mediação de interações da planta com insetos diurnos e noturnos. ${ }^{30}$ Os voláteis são afetados por fatores abióticos como umidade do solo e ar, intensidade luminosa, fotoperíodo e nível de fertilização. ${ }^{31}$ Estas variações oferecem aos inimigos naturais informações não somente a respeito da presa, mas também sobre a planta e seu estado fisiológico.

Os inimigos naturais respondem aos voláteis de forma específica. ${ }^{15}$ Porém, em muitos estudos tem se reportado a falta de especificidade no sistema tritrófico. ${ }^{32}$ Possivelmente, a especificidade é mais importante para inimigos naturais especialistas ou oligófagos. ${ }^{15}$ A mistura de voláteis induzida pode variar quantitativa - (incremento dos mesmos compostos) ou qualitativamente (indução de compostos novos) daquela emitida por plantas danificadas mecanicamente. ${ }^{33} \mathrm{~A}$ atração da vespa parasita Cotesia marginiventris (Cresson, 1865) (Hymenoptera: Braconidae) às plantas de milho (Zea mays L.) danificadas, por exemplo, parece basear-se em diferenças qualitativas, mais que em diferenças quantitativas. ${ }^{34}$ Uma vez que diferentes espécies de plantas podem emitir os mesmos compostos, tem-se proposto que a orientação olfativa dos insetos está baseada em variações, geralmente de uns poucos compostos ${ }^{14,35}$ dentre as centenas que podem ser emitidos pelas plantas. ${ }^{36}$

\section{Comunicação planta-planta: $O$ alerta às plantas vizinhas}

Desde 1983, quando foram realizados os primeiros experimentos que demonstraram a interação entre plantas, ${ }^{37} \mathrm{o}$ papel dos voláteis induzidos nas interações planta-planta tem sido intensamente debatido. ${ }^{38}$ Porém, nos últimos anos tem-se acumulado evidências moleculares e ecológicas sobre a interação entre plantas, tanto por testes de laboratório, como de campo. Os voláteis de folhas verdes (VFVs) induzem a transcrição de genes envolvidos nas respostas de defesa em Arabidop i $^{39}$ e estão envolvidos na rota dos octadecanoides, responsável pela produção do ácido jasmônico. ${ }^{40}$ Os terpenoides possuem efeito semelhante em feijão-de-lima (Phaseolus lunatus L.). ${ }^{41}$ Em milho, a exposição de plantas sadias a plantas atacadas por Spodoptera littoralis (Boisduval, 1833) (Lepidoptera: Noctuidae) ativa a expressão de genes de defesa e iniciaram a emissão de voláteis induzidos. ${ }^{42} \mathrm{~A}$ produção de néctar extrafloral, outra defesa indireta das plantas, também é induzida em plantas vizinhas após a exposição a compostos voláteis, ${ }^{43}$ o qual pode aumentar a sobrevivência de artrópodes predadores. ${ }^{44}$

Os voláteis induzidos após o ataque dos herbívoros parecem "preparar" as plantas vizinhas para um possível ataque futuro. (Figura 2). ${ }^{42,45}$ Esta preparação é um processo pelo qual as plantas adquirem um estado de habilidade para expressar as defesas induzidas mais rapida ou agressivamente, em casos futuros de estresse biótico ou abiótico. Em milho, os indivíduos de $S$. littoralis que se alimentaram de plantas expostas a voláteis induzidos após a herbivoria tiveram menores taxas de crescimento e o parasitoide $C$. marginiventris preferiu os voláteis emitidos por plantas após a exposição a voláteis induzidos após a herbivoria. ${ }^{42}$ Resultados similares têm sido reportados para o ácaro predador Phytoseiulus persimilis Athias-Henriot, 1957 (Acarina: Phytoseiidae), o qual preferiu plantas após a prévia exposição de Phaseolus lunatus induzida pelo ácaro Tetranychus urticae Koch, 1936 (Acari: Tetranychidae) ${ }^{46}$

Considerando-se que o estímulo precedente inicia um estado de "alerta" que não confere resistência propriamente dita, mas permite

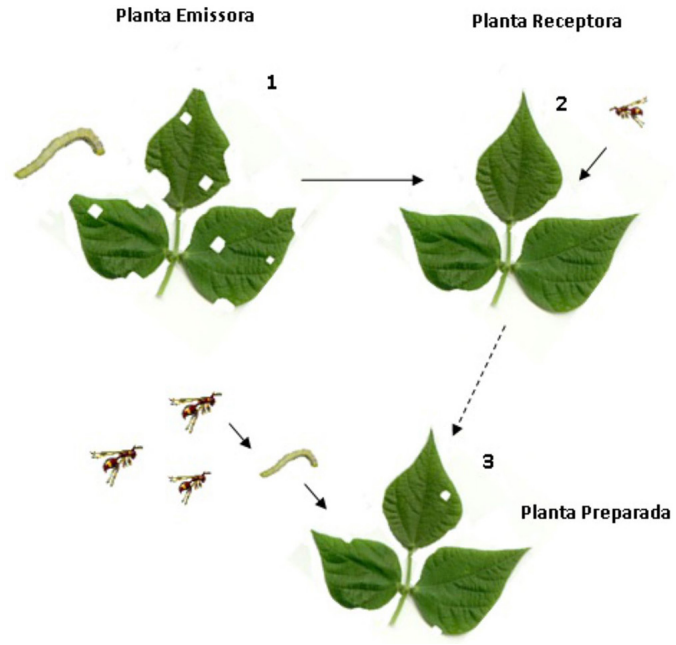

Figura 2. "Comunicação" entre plantas: plantas atacadas induzem plantas vizinhas não-atacadas a iniciar o processo de defesa. A planta emissora é induzida, após a herbivoria, e emite voláteis para a atmosfera (1). Esses são percebidos pela planta vizinha receptora, que ativa os mecanismos de defesa tais como ativação de genes envolvidos na síntese de proteínas de defesa e de voláteis (2). Essas podem atrair inimigos naturais. As plantas também são preparadas ("primed") para responder mais rapidamente ao futuro ataque de herbívoros (3) 
uma resposta induzida acelerada em caso de ataque, podemos assumir que uma das suas vantagens é o baixo custo energético da ativação de uma resposta de defesa induzida.

Existem muitos compostos químicos envolvidos nas interações entre plantas. Estes incluem VFVs $\left[(E)\right.$-2-hexenal, ${ }^{47}(Z)$-3-hexen-1$\mathrm{ol}^{48} \mathrm{e}$ acetato de $(Z)$-3-hexen-1-ila ${ }^{49}$, terpenos, como mirceno e misturas de ocimeno $\left[(E)\right.$ - $\beta$-ocimeno, $(Z)$ - $\beta$-ocimeno e allo-ocimeno $\left.{ }^{50}\right]$ e formas voláteis de fitohormônios [jasmonato de metila (MeJA) ${ }^{51}$ salicilato de metila (MeSA) ${ }^{52}$ e etileno (ET)]. ${ }^{53}$

\section{Efeito dos voláteis induzidos nas comunidades ecológicas}

Quando uma planta é atacada por um herbívoro, todos os organismos presentes no meio ambiente podem responder aos voláteis induzidos. Além de mediar interações tritróficas e interações intraespecíficas (com plantas vizinhas), os voláteis induzidos após o ataque dos herbívoros podem afetar outros individuos da mesma espécie ou outras espécies herbívoras. Alguns herbívoros podem ser atraídos e outros repelidos pelos voláteis induzidos após a herbivoria. Os estudos sugerem que tanto lepidópteros como afidios são, em geral, repelidos por plantas infestadas. O lepidóptero Heliothis virescens Fabricius, 1777 (Lepidoptera: Noctuidae) prefere plantas sadias para ovipositar e é repelido por plantas danificadas por co-específicos. ${ }^{30}$ Da mesma maneira, o pulgão-do-milho Rhopalosiphum maidis Fitch, 1856 (Hemoptera: Aphididae) é repelido por voláteis induzidos por S. littoralis. ${ }^{54}$ Já os besouros são atraídos pelos voláteis emitidos após a herbivoria. Por exemplo, Leptinotarsa decemlineata Say, 1824 (Coleoptera: Chrysomelidae) prefere os voláteis emitidos por plantas danificadas por indivíduos da mesma espécie. ${ }^{55}$ Possivelmente, esta estratégia debilita as defesas químicas da planta, a qual pode ser principalmente empregada por organismos especialistas adaptados a certos compostos tóxicos das plantas. ${ }^{6}$ Poucos estudos têm avaliado os efeitos da herbivoria nas interações da planta com agentes polinizadores, os quais respondem a voláteis emitidos pelas flores. Porém, a maioria dos estudos apontam que a herbivoria, tanto de partes vegetativas como de flores, pode reduzir as visitações pelos polinizadores..$^{56}$
Os voláteis induzidos pela oviposição também podem alterar as emissões constitutivas da planta. ${ }^{22,57}$ A oviposição de Spodoptera frugiperda Smith, 1797 (Lepidoptera: Noctuidae) suprime a emissão de compostos voláteis emitidos por milho. ${ }^{58}$ Embora em milho não se tenha avaliado as respostas de outros herbívoros à oviposição de S. frugiperda, em Brachiaria brizantha, a oviposição de Chilo partellus Swinhoe, 1885 (Lepidoptera: Cambridae) reduz a colonização do herbívoro. ${ }^{59}$ Segundo Bernasconi e colaboradores, ${ }^{54}$ os voláteis induzidos poderiam alertar outros herbívoros sobre a produção de compostos tóxicos pela planta, sobre a presença potencial de competidores, assim como de inimigos naturais que são atraídos após a indução.

\section{PRINCIPAIS GRUPOS QUÍMICOS QUE ATUAM COMO VOLÁTEIS INDUZIDOS APÓS O ATAQUE DOS HERBÍVOROS}

Em geral, os voláteis induzidos após a herbivoria são formados principalmente por aldeídos, e por álcoois C6 e seus ésteres, produzidos através da rota da enzima lipoxigenase (LOX) e terpenoides. Os compostos derivados da via LOX (rota dos octadecanoides) são conhecidos como voláteis de folhas verdes (VFVs) e são emitidos principalmente quando as folhas são danificadas mecanicamente. Estes podem constituir mais de $50 \%$ da emissão de partes danificadas em algumas espécies de planta. ${ }^{60}$ Nos tecidos com dano mecânico ou de alimentação, os VFVs são formados rapidamente, enquanto que em tecidos de plantas saudáveis e intactas a quantidade destes compostos é baixa. ${ }^{61}$ Por isso, considera-se que eles sejam emitidos em forma passiva pela planta. No entanto, já foi observada a emissão sistemática do acetato de (Z)-3-hexen-1-ila como resposta a herbivoria de larvas de Spodoptera exigua Hübner, 1808 (Lepidoptera: Noctuidae), em plantas de algodão (Gossypium hirsutum L.) ${ }^{62}$ e a especificidade na emissão destes compostos dentro de uma mesma espécie de planta dependendo da espécie de herbívoro. ${ }^{63}$

Na rota de formação dos VFVs, o composto (Z)-3-hexenal é o primeiro produto formado através da oxigenação do ácido linolênico pela ação da LOX (Figura 3), formando o ácido 13-hidroperoxi-linolênico

Ácido Pirúvico (AP)/

Gliceraldeído-3-fosfato (GAF)

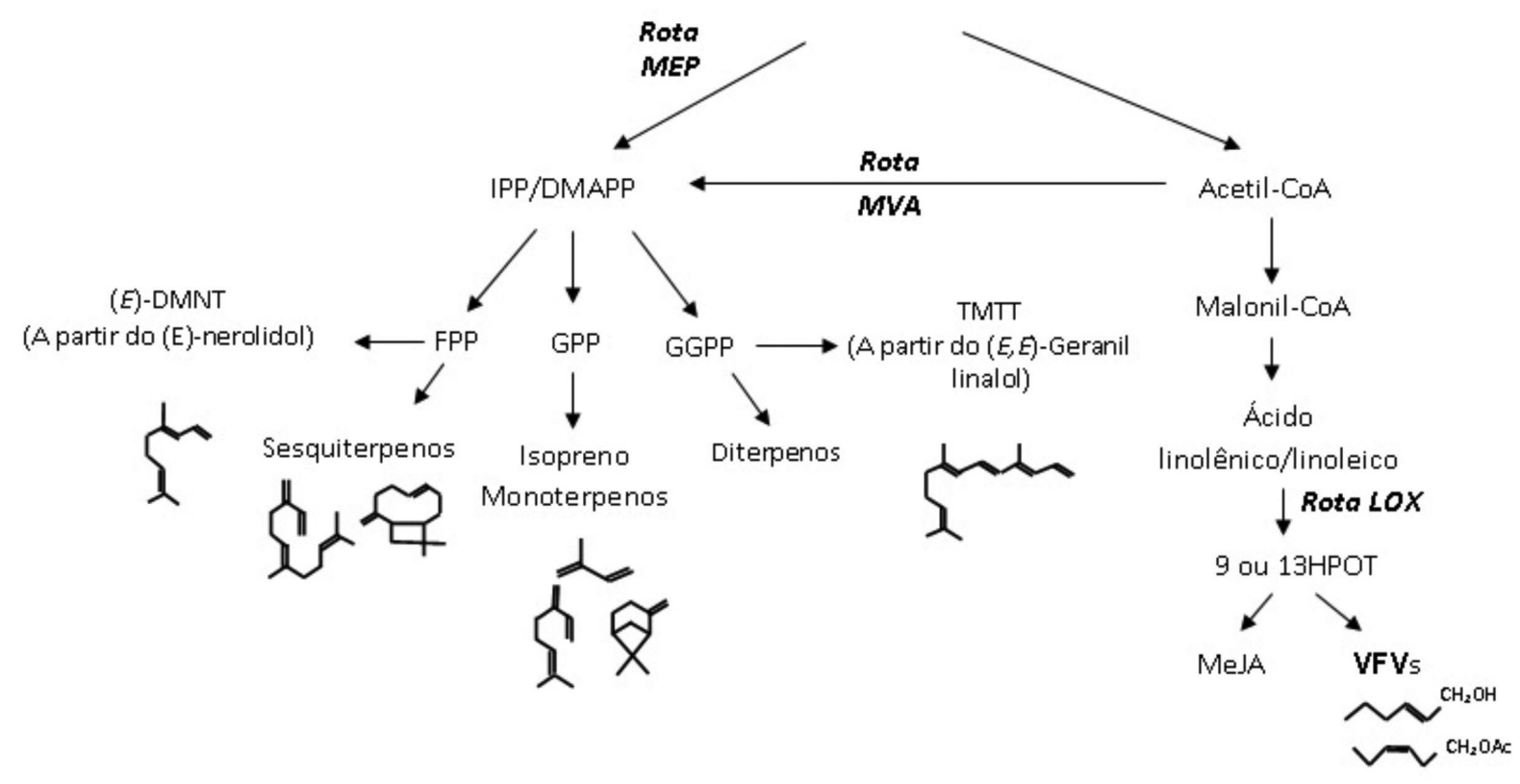

Figura 3. Rotas metabólicas para a produção dos dois principais grupos de voláteis induzidos após a herbivoria (Modificado de Schoonhoven et al.) ${ }^{l}$ 
(13HPOT). Posteriormente, o 13HPOT é metabolizado pela 13-hidroperoxidoliase (13HPL) resultando na formação de (Z)-3-hexenal e do ácido 12-oxo-(Z)-9-dodecenoico. O composto n-hexanal é formado da mesma forma, mas a partir do ácido linoleico. A isomerização enzimática e não enzimática do $(Z)$-3-hexenal resulta na formação do (E)-2-hexenal. Esses aldeídos C6 são convertidos nos alcoóis correspondentes através da enzima desidrogenase. Já a enzima acetiltransferase é a responsável pela formação dos acetatos correspondentes. ${ }^{64} \mathrm{O}$ composto $13 \mathrm{HPOT}$ é precursor dos VFVs, mas também faz parte da rota dos octadecanoides, ou seja, da produção do ácido jasmônico (JA). Este ácido é um dos responsáveis pela produção de voláteis da resposta indireta após a herbivoria e poderia competir por 13HPOT. No entanto, devido à localização diferenciada deste precursor nas células, contribui para a ativação de ambas rotas em resposta a herbivoria. ${ }^{65}$

O outro grupo importante de voláteis induzidos após o ataque dos herbívoros são os terpenoides (rota dos isoprenoides) (Figura 4), os quais podem dominar a emissão de algumas espécies de plantas como o milho. ${ }^{66}$ Após a indução pela herbivoria, muitos compostos voláteis emitidos constitutivamente aumentam. Neste caso, os voláteis emitidos são aqueles já armazenados anteriormente na planta. Além disso, outros compostos podem ser produzidos de novo ${ }^{67}$ Estes compostos têm sido reconhecidos como semioquímicos importantes nas relações planta-inseto. ${ }^{60,66} \mathrm{~A}$ indução destes compostos varia entre espécies de planta, mas dois homoterpenos,

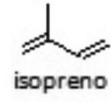

$$
\text { isopreno }
$$<smiles>CC1CCC(C(C)C)C(=O)C1</smiles>

mentona

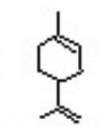

limoneno

Wonoterpenos monocídicos<smiles>C=C(C)CC/C=C(/C)CCC=C(C)C</smiles><smiles>CC(C)=CCCC(C)=CCCC(C)(C)O</smiles>

B-farneseno nerolidol

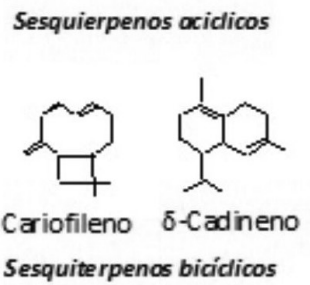

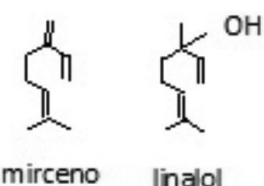

Monoterpenos aciclicos
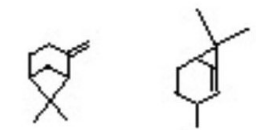

pineno

careno
Monoterpenos bicíclicos

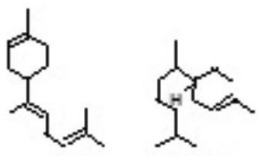

bisaboleno zingiber eno
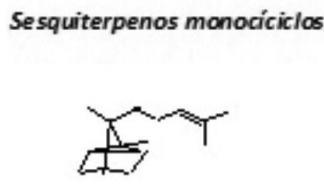

$\alpha$-santaleno

Sesquiterpenos tricíclicos

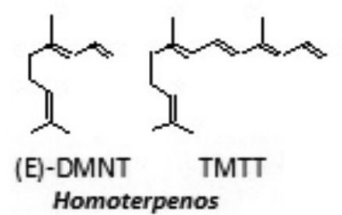

Figura 4. Estruturas representativas dos isoprenoides (isopreno e terpenoides) emitidos pelas plantas

(E)-4,8-dimetil-1,3,7-nonatrieno (DMNT) e (E,E)-4,8,12-trimetil1,3,7,11-tridecatetraeno (TMTT), são induzidos de forma geral, por muitas espécies de plantas. ${ }^{60}$

A biossíntese do grupo dos isoprenoides, ao qual pertencem os terpenoides tem sido amplamente estudada ${ }^{36}$ (Figura 3). De modo geral, a produção começa a partir de precursores de cinco carbonos, o isopentenil difosfato (IPP) e seu isômero, dimetilalil difosfato (DMAPP), que são produzidos por duas rotas biossintéticas. No citoplasma, a rota do mevalonato (MVA) produz IPP a partir de moléculas utilizando a acetil coenzima A. A enzima farnesil pirofosfato sintase catalisa a formação de duas moléculas de IPP e uma de DMAPP para formar farnesil pirofosfato (FPP), o precursor dos sesquiterpenos. Nos plastídios, o IPP é derivado do piruvato e do gliceraldeido-3-fosfato pela via do 2-C-metil-D-eritritol 4-fosfato (MEP). O isômero é usado na síntese de isopreno. A enzima geranil pirofosfato sintase catalisa a condensação de uma molécula de IPP e uma de DMAPP para formar geranil pirofosfato (GPP), o precursor dos monoterpenos. Da mesma forma, a enzima geranilgeranil pirofosfato sintase catalisa a condensação de uma molécula de DAPP com três de IPP para formar geranilgeranil pirofosfato (GGPP), o precursor dos diterpenos ${ }^{36}$ As vias do MVA e MEP são independentes, porém, pode haver interação entre elas. Aparentemente, até $80 \%$ do IPP utilizado na biossíntese de sesquiterpenos após a herbivoria vem da rota MEP. ${ }^{68}$ Os dois homoterpenos, DMNT e TMTT, são produzidos a partir do sesquiterpenoide $(E)$-nerolidol e do diterpenoide $(E, E)$-geranil linalol, respectivamente. ${ }^{69}$

A diversidade estrutural dos terpenoides é grande devido às terpeno sintases (TPSs) que utilizam os diferentes prenil difosfatos como substratos para sintetizar monoterpenos a partir do geranil difosfato (GDP), sesquiterpenos a partir do farnesil difosfato (FDP) e diterpenos a partir do geranilgeranil difosfato (GGDP).$^{70}$ Já foram descritos mais de 2.500 monoterpenos e 5.000 sesquiterpenos.

As emissões induzidas após a herbivoria também podem incluir fenil propanoides/benzeinodes. Porém, suas rotas metabólicas não têm sido estudadas em detalhe. A L-fenilalanina produzida pela rota do ácido chiquímico é convertida em ácido $(E)$-cinâmico, reação que é catalisada pela enzima L-fenilalanina amonia-liase. ${ }^{36} \mathrm{O}$ ácido salicílico e seu éster volátil, salicilato de metila (MeSA), são produzidos por esta via. ${ }^{71}$

\section{MECANISMOS E ROTAS METABÓLICAS DE INDUÇÃO DE VOLÁTEIS}

A indução de voláteis após a herbivoria e as defesas induzidas, em geral, implicam a ativação de vias metabólicas orquestradas e organizadas. O uso de plantas transgênicas ou mutantes que não são capazes de produzir ou expressar respostas de defesa e a aplicação endógena de hormônios e outros compostos têm permitido incrementar o conhecimento destes mecanismos no nível molecular. ${ }^{72}$ Num primeiro passo, as respostas são desencadeadas por elicitores derivados do herbívoro. A emissão dos voláteis induzidos após o ataque dos herbívoros não pode ser imitada pelo dano mecânico, mas sim quando os elicitores isolados das secreções orais entram em contato com áreas danificadas da planta. ${ }^{73}$ Após a herbivoria, ocorre uma despolarização do potencial da membrana e um influxo de cálcio $\left(\mathrm{Ca}^{2+}\right)$. O dano mecânico produz acumulação de espécies de oxigênio reativas como superóxido $\left(\mathrm{O}_{2}^{-}\right)$e peróxido de hidrogênio $\left(\mathrm{H}_{2} \mathrm{O}_{2}\right)$ além do óxido nítrico, que possuem funções regulatórias de defesa, ${ }^{2,74}$ mas não resulta na produção de novo de voláteis. Porém, após o dano mecânico continuo, ocorre acumulação de transcrições de uma MAP quinase a qual parece estar envolvida na produção do ácido jasmônico, e resulta na produção de voláteis que se assemelham àqueles induzidos após a herbivoria (Figura 5). ${ }^{75}$ 


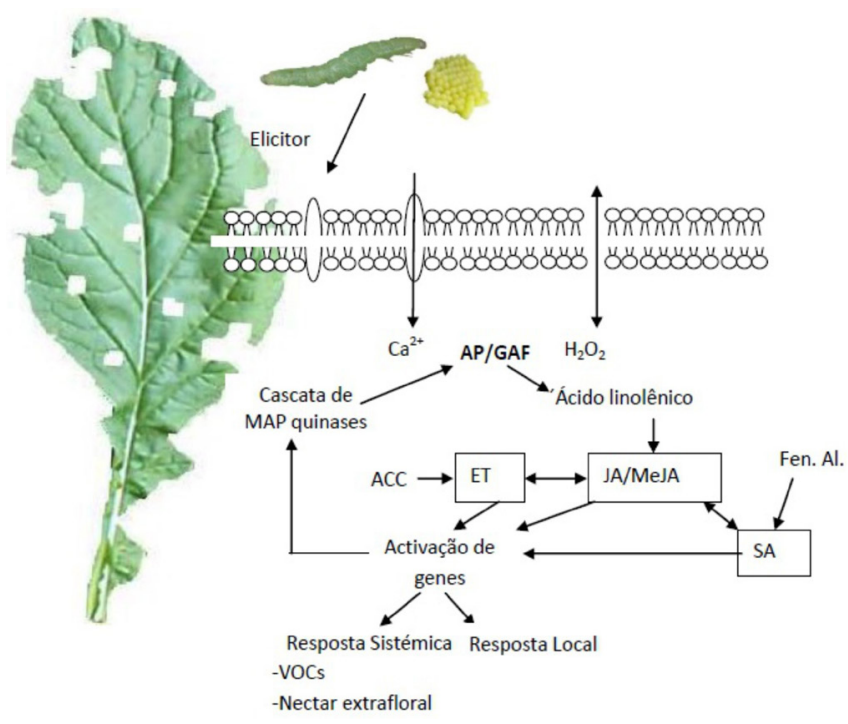

Figura 5. Mecanismos básicos de indução das defesas indiretas das plantas após a herbivoria (Baseado em Arimura) ${ }^{2}$

O ácido jasmônico (JA), seus precursores e compostos relacionados, atuam como estímulo principal na resposta da planta à herbivoria, ativando os genes que respondem local e sistematicamente ao stress. Estes genes envolvidos na síntese de compostos de defesa incluem as terpeno sintases para a produção de voláteis que atraem os inimigos naturais. ${ }^{76}$ Embora os jasmonatos sejam moléculas-chave na ativação de respostas para a maioria de herbívoros, ${ }^{77}$ outros hormônios, principalmente o ácido salicílico, atuam como moléculas sinalizadoras. As rotas metabólicas induzidas na planta em resposta a fatores abióticos e bióticos parecem ser redundantes, porém as plantas ajustam suas respostas defensivas a um herbívoro específico através de sinais moleculares de três rotas, ácido jasmônico, etileno e ácido salicílico, ativadas em diferentes graus. ${ }^{78}$

\section{Elicitores}

$\mathrm{Na}$ atualidade vários elicitores oriundos dos herbívoros pertencentes a várias ordens taxonômicas já foram identificados (Figura 6). ${ }^{79} \mathrm{Na}$ secreção oral de lagartas (Lepidoptera) existem dois tipos de substâncias elicitoras encontradas: os conjugados de ácidos graxos e aminoácidos e as enzimas líticas. ${ }^{73} \mathrm{~A}$ volicitina, $\mathrm{N}$-(17-hidroxilinolenoil)-L-glutamina foi o primeiro conjugado de ácidos graxos e aminoácidos identificado. No início dos anos 90, este composto foi isolado, identificado e sintetizado a partir da saliva da lagarta $S$. exigua, e quando aplicado em plantas de milho causa a liberação dos mesmos voláteis liberados após o dano realizado por lagartas. Porém, não tem os mesmos efeitos no feijão-de-lima, também hospedeiro de $S$. exigua, assim mais estudos são necessários para se avaliar a função elicitora da volicitina.$^{80}$ Além de lepidópteros, recentemente foram isolados ácidos graxos conjugados e aminoácidos da secreção oral de larvas de moscas das frutas e grilos que induzem a emissão de voláteis. ${ }^{79} \mathrm{Na}$ secreção oral do gafanhoto-sul-americano Schistocerca americana Drury, 1773 (Orthoptera: Acrididae) foram identificados elicitores conhecidos como caeliferinas que induzem a emissão de voláteis. ${ }^{81}$ As caeliferinas são compostas de ácidos graxos hidroxi sulfatados saturados e monoinsaturados, nos quais o carbono é funcionalizado com uma hidroxila sulfatada ou com uma carboxila conjugada a uma glicina através de uma ligação amida.

No grupo das enzimas líticas, um segundo elicitor foi identificado alguns anos depois da volicitina, a $\beta$-glucosidase ${ }^{73}$ Esta enzima lítica está presente no regurgito de lagartas de Pieris brassicae (Linnaeus,<smiles>CC(O)/C=C\C/C=C\C/C=C\CCCCCCCC(=O)N[C@@H](CCC(N)=O)C(=O)O</smiles><smiles>O=C(O)C(CCC/C=C/CCCCCCCCCOS(=O)(=O)O)OS(=O)(=O)O</smiles><smiles></smiles>

Inceptina derivada de Vigna unguiculato (L.) Walp.

Figura 6. Estruturas de alguns elicitores derivados de herbívoros envolvidos na produção e emissão de voláteis que atraem inimigos naturais (Baseado em Maffei et al. $)^{79}$

1758) (Lepidoptera: Pieridae) e, quando aplicado em folhas de couve (Brassica oleraceae L.) com danos mecânicos, resulta na emissão de voláteis que atraem parasitoides da espécie Cotesia glomerata (Linnaeus, 1758) (Hymenoptera: Braconidae). Outras enzimas líticas, tais como glicose oxidases de lepidópteros e fosfatase alcalina de mosca branca, foram identificadas, mas suas funçoes como elicitores não foram comprovadas. Na saliva do pulgão-da-espiga Sitobion avenae (Fabricius, 1775) e Schizaphis graminum (Rondani, 1852) (Hemiptera: Aphididae) também foram encontrados elicitores (polifenol oxidases) de respostas de defesa em trigo (Triticum aestivum L.). ${ }^{82}$

Recentemente foi encontrado um peptídeo na secreção oral de S. frugiperda que induz a emissão de voláteis. A inceptina, como tem sido denominado o elicitor, é um peptídeo que contém pontes dissulfeto (+ICDINGVCVDA) derivado de uma ATP sintase do cloroplasto da planta hospedeira. ${ }^{83}$ Também foram encontradas substâncias elicitoras ainda não identificadas na saliva de adultos e ninfas de Lygus hesperus (Knight, 1917) (Hemiptera: Miridae), cuja alimentação provoca a emissão de voláteis no local de alimentação em plantas de algodão e milho. A alimentação por L. hesperus também induziu a emissão sistêmica de voláteis similares, porém mais complexos que os voláteis emitidos no local de alimentação. Extratos de glândula salivar de L. hesperus são capazes de induzir a emissão dos mesmos voláteis emitidos por plantas infestadas por insetos e tratadas com o elicitor volicitina. Portanto, a indução da emissão de voláteis de plantas é causada por um elicitor presente na glândula salivar do inseto. ${ }^{84}$ 
Em alguns casos, a indução de voláteis após a oviposição é o resultado do dano mecânico e de substâncias secretadas durante o processo como em alguns besouros, moscas-de-serra e percevejos. ${ }^{85}$ Porém, em outros casos, mesmo que o inseto não cause nenhum dano na superfície da planta durante a oviposição, ocorre emissão de voláteis como reportado em espécies de Lepidoptera. ${ }^{22,57}$ As respostas da planta à oviposição são originadas dos ovos ou das substâncias secretadas pelas fêmeas durante a oviposição.$^{85}$ No entanto, a base química da ativação para a emissão dos voláteis ainda é desconhecida. ${ }^{14}$

Além dos elicitores naturais é importante mencionar que a emissão de voláteis pela planta pode ser induzida pela aplicação exógena de hormônios vegetais tais como ácido jasmônico e ácido salicílico, assim como outros elicitores de origem microbiana ${ }^{6,79}$ os quais poderiam ser aplicados no desenvolvimento de estratégias para o controle de pragas. Por exemplo, a soja (Glycine max L.) quando tratada com a cis-jasmona emite voláteis como o canfeno, mirceno, $(E)$-ocimeno, MeSA e TMTT. São voláteis similares aos liberados após o ataque de percevejos que atraem o parasitóide de ovos Telenomus podisi (Ashmead, 1893) (Hymenoptera: Scelionidae). ${ }^{86}$

\section{Hormônios envolvidos na indução de voláteis após a herbivoria}

O papel do ácido jasmônico (JA) na defesa das plantas foi reconhecido em 1990 por Farmer e Ryan, ${ }^{87}$ quando demonstraram pela primeira vez que o jasmonato de metila induz a atividade de inibidores de proteases, que são moléculas que funcionam como compostos de defesa direta. O JA se acumula rapidamente após a herbivoria ou dano mecânico. Está envolvido na ativação de genes de defesa, após a qual ocorre a produção de compostos de baixo e alto peso molecular utilizados na defesa das plantas contra os insetos herbívoros, como os inibidores de protease e as fitoalexinas. ${ }^{88}$ Estes genes de defesa são ativados, por sua vez, pelas oxilipinas pentacíclicas, presentes durante o processo de transdução dos sinais químicos. ${ }^{89} \mathrm{O}$ JA é a molécula mais importante na regulação dos voláteis induzidos após o ataque dos herbívoros e está conectado à preparação das plantas a futuros ataques. ${ }^{42}$

O SA, por sua vez, é um regulador de crescimento que funciona como sinalizador, ativando as respostas das plantas após o ataque de patógenos. $\mathrm{O}$ acúmulo do $\mathrm{SA}$ nos tecidos das plantas induz a resistência sistêmica adquirida (RSA) ${ }^{90}$ uma forma de resistência induzida. No caso da herbivoria, o papel do SA não é bem esclarecido. É possível que seja menos importante nas respostas ao dano pelos herbívoros mastigadores. Porém, herbívoros sugadores, como moscas brancas e afídeos, que possuem uma interação íntima e de longa duração com a célula vegetal, ${ }^{7}$ ativam respostas de defesa que dependem do SA do mesmo modo que os patógenos..$^{90}$ Por exemplo, em A. thaliana, os ARNs regulados por SA aumentam local e sistemicamente em resposta à alimentação da mosca branca Bemisia tabaci (Gennadius, 1889) biótipo B (Hemiptera: Aleyrodidae), enquanto que os ARNs regulados por JA e etileno mantêm-se normais ou têm declínio, ${ }^{91}$ indicando o papel de destaque do SA na resposta das plantas após alimentação de insetos sugadores. O SA altera a atividade ou síntese de enzimas, aumenta a expressão de genes de defesa, de maneira distinta ao JA, potencializa respostas de defesa, e/ou aumenta a geração de radicais livres. ${ }^{92}$

Embora, o JA e o SA sejam antagonistas, ambos são necessários para induzir respostas após a herbivoria, pois ambos controlam coordenadamente as respostas de defesa da planta. Já está estabelecido que o JA tem um papel muito importante na regulação da emissão de voláteis induzidos após o ataque dos herbívoros, incluindo a emissão de MeSA, como demonstrado em tomate (Solanum lycopersicum L. . ${ }^{93}$ Porém, estudos com a planta modelo A. thaliana demostraram que a emissão de voláteis após a alimentação de lagartas da espécie Pieris rapae (Linnaeus, 1758) (Lepidoptera: Pieridae) é mediada por mudanças na concentração desses dois hormônios e resulta na atração de parasitoides da espécie Cotesia rubecula (Marshall, 1885) (Hymenoptera: Braconidae). ${ }^{72}$ Da mesma forma, o tratamento de feijão-de-lima através de aplicações de várias quantidades de JA e SA resulta na emissão de uma mistura característica de voláteis que atraem inimigos naturais. ${ }^{94}$

O etileno (ET) é uma terceira molécula envolvida nas respostas induzidas da plantas. ${ }^{74}$ Em Arabidopsis, o ET e o JA agem juntos na indução da expressão de defensinas e genes PR que codificam proteínas de defesa localizadas em vacúolos. ${ }^{95}$ Nesta espécie de planta, esses dois compostos também agem em sequência para induzir a tolerância sistêmica (contra patógenos), chamada de resistência sistêmica induzida (RSI). ${ }^{90}$ A produção do etileno em culturas com células de tomate foi comprovada após dano e ação de elicitores como a sistemina, fragmentos oligogalacturonídeos e JA, além disso, este composto pode potencializar a ação do JA em resposta ao dano. ${ }^{53} \mathrm{~A}$ biossíntese do ET, assim como a do JA, é estimulada após o dano mecânico. ${ }^{96}$

No caso dos voláteis emitidos pela oviposição, são poucos os esforços para elucidar os mecanismos de indução dos voláteis. Porém, sabe-se que o ácido jasmônico está envolvido na mediação da indução desses voláteis, pois em Ulmus minor Mill. e Pinus sylvestris L., a adição de ácido jasmônico ao suplemento de água por três dias também foi responsável pela atração de parasitoides. ${ }^{97}$ É possível que a presença de ácido jasmônico acumulado em ovos atue como uma molécula sinal para a emissão de voláteis após a oviposição. ${ }^{98}$

\section{ATAQUE MÚLTIPLO E O “CROSS TALK”: EFEITO NA DEFESA INDIRETA}

Ao nível molecular, as rotas metabólicas do JA e SA atuam de maneira antagonista. A ativação da rota do SA pode suprimir a expressão de genes de defesa dependentes do JA, possivelmente devido à inibição na biossíntese desse hormônio. Da mesma forma, a ativação da rota do JA pode suprimir a expressão de genes dependentes do SA. ${ }^{99}$ Este processo pelo qual as rotas podem atuar de maneira sinergista ou antagonista é conhecida como "cross talk" e permite à planta responder da maneira mais apropriada aos estímulos externos e, possivelmente, a minimizar custos de defesa. Como já mencionado, os insetos mastigadores, tais como lagartas de lepidópteros e os insetos sugadores, tais como mosca brancas e afídeos, ativam essas rotas de forma diferenciada. Por exemplo, a alimentação de $B$. tabaci biotipo B suprime as defesas dependentes do ácido jasmônico. ${ }^{91}$ Estas defesas também podem ser suprimidas após a oviposição, tal como recentemente demonstrado para $P$. brassicae, a qual pode suprimir as respostas dependentes do ácido jasmônico em A. thaliana. ${ }^{100}$

As plantas podem ser atacadas por vários micro e macroorganismos simultaneamente. Recentemente, baseados na evidência molecular, vários estudos têm dado atenção aos efeitos da herbivoria múltipla na indução das defesas na planta, incluindo a emissão de voláteis induzidos, que podem impactar a resposta dos inimigos naturais. Por exemplo, após infestações isoladas dos insetos fitófagos, S. littoralis (foliar) e Diabrotica virgifera virgifera (LeConte, 1868) (Coleoptera: Chrysomelidae) (radicular), seus respectivos inimigos naturais, C. marginiventris e o nematoide Heterorhabitis megidis (Poinar, Jackson e Klein, 1987) (Rhabditida: Heterorhabditidae), são atraídos para as plantas hospedeiras. Porém, em situação de dupla infestação (aérea e subterrânea), a atração é reduzida significativamente. Apesar do efeito negativo na atração dos inimigos naturais, apenas os voláteis das raízes $\left((E)\right.$ - $\beta$-cariofileno) são reduzidos. ${ }^{101}$ O comportamento de forrageamento do parasitoide $C$. glomerata ao seu hospedeiro P. brassicae em mostarda preta (Brassica nigra L.) é altamente alterado quando as plantas são expostas à herbivoria radicular por larvas de Delia radicum (Linnaeus, 1758) (Diptera, 
Anthomyiidae), observando-se preferência do parasitoide por lagartas que se alimentam de plantas com sistema radicular não atacado. ${ }^{102}$ Nesse estudo, as plantas expostas à herbivoria radicular emitiram misturas de voláteis com altos níveis de compostos derivados de enxofre, que são reportados na literatura como altamente tóxicos para insetos. A infestação por $B$. tabaci suprime a síntese de JA induzida pelo ácaro herbívoro $T$. urticae e a emissão de (E)- $\beta$-ocimeno. Como resultado, a atração do ácaro predador $P$. persimilis é reduzida. ${ }^{103}$

\section{AS DEFESAS INDIRETAS NA AGRICULTURA}

A identificação e manipulação de compostos químicos mediadores de atividades vitais dos artrópodes oferecem uma ampla gama de possibilidades para o desenvolvimento de estratégias de controle de pragas mais sustentáveis, considerando-se que os sinais químicos são a fonte primária de informação para estes organismos. A identificação e o conhecimento das funções e natureza dos semioquímicos permite a manipulação com a finalidade do controle de pragas agrícolas, já apresentadas em casos bem sucedidos. Os feromônios são sintetizados mais facilmente e, na atualidade, já são utilizados em armadilhas para o monitoramento, coleta em massa ou controle por meio da confusão sexual. ${ }^{104}$ Além disso, o conhecimento sobre a função dos voláteis emitidos em forma constitutiva nas interações planta-herbívoro tem permitido o uso de plantas armadilhas e plantas repelentes na redução da pressão de pragas na cultura principal. ${ }^{105}$ No entanto, esses estudos foram principalmente realizados em laboratório nas últimas três décadas. Por isso, o papel dos voláteis induzidos na natureza tem recebido críticas devido à falta de modelos em campo. ${ }^{106}$ Tentando aumentar o número desses estudos, muitos pesquisadores vêm se dedicando a avaliar em campo as interações ecológicas, assim como as possibilidades de utilizá-los em programas de controle de praga (Tabela 1). Sem dúvida, os voláteis induzidos após o ataque dos herbívoros têm potencial para o desenvolvimento de estratégias de controle de praga, porém sugere-se que não devem ser vistos como uma estratégia isolada, mas como um dos componentes de um programa de manejo integrado. ${ }^{107}$

\section{Aplicação exógena de elicitores dos voláteis induzidos}

Já foi comprovado que a aplicação exógena de elicitores induz a emissão de voláteis (por exemplo, o JA e seus derivados: MeJA e

Tabela 1. Estudos de campo que resaltam o potencial dos voláteis induzidos após o ataque dos herbívoros na agricultura ${ }^{\mathrm{a}}$

\begin{tabular}{llcl}
\hline Cultura & Compostos avaliados & Método de Aplicação & Principais Resultados \\
\hline Tomate $^{111}$ & JA (Ácido Jasmônico) & $\begin{array}{c}\text { Aspersão às } \\
\text { plantas }\end{array}$ & $\begin{array}{l}\text { Maior atratividade e retenção dos parasitoides no } \\
\text { campo. O parasitismo de Hyposoter exiguae Viereck } \\
\text { (Hym.: Ichneumonidae) sobre S. exigua aumentou } \\
\text { em 3 vezes. }\end{array}$ \\
\hline
\end{tabular}

$\begin{array}{lll}\text { Uva }^{127} & \text { MeSA, MeJA e acetato de (Z)-3-hexen-1-ila } & \text { DLC }\end{array}$ inimigos naturais, principalmente de insetos predadores generalistas, mas também de parasitoides dos géneros Metaphycus (Hym.: Encyrtidae) e Anagrus (Hym: Myrmaridae).

\begin{tabular}{llll}
\hline Soja $^{128}$ & 2-fenil-etanol e MeSA & DLC & Joaninhas (Coleoptera: Coccinellidae) e moscas da
\end{tabular} família Syrphidae foram atraídas por estes compostos. A eficiência na atração dependeu da concentração usada. No caso de MeSA, a abundância de afídeos reduziu pela presênça do composto.

$\begin{array}{ll}\text { Maçã } \tilde{a}^{117,118} & \text { Decanal, MeSA, 2-fenil-etanol, }(Z) \text {-jasmona, p-an- } \\ \text { isaldeído, anetol, esqualeno, iridodial (feromônio) }\end{array}$ acetato de (Z)-3 hexen-1-ila, (Z)-3-Hexen-1-ol e benzaldeído
DLC (borracha)

Os compostos que atraíram o maior número do herbívoro Argyresthia conjugella foram 2-feniletanol, MeSA e decanal. A mistura de 2-fenil-etanol e anetol atraiu mais machos que as armadilhas com feromônio sexual

$\mathrm{O}$ tratamento de esqualeno foi muito atrativo ao Chrysopa nigricornis Burmeister (Neuroptera: Chrysopidae) sozinho ou em combinação com MeSA ou iridodial.

\begin{tabular}{|c|c|c|c|}
\hline Algodão $^{129}$ & $\begin{array}{l}\text { DMNT, acetato de (Z)-3-hexen-1-ila, nonanal, octanal, } \\
\text { decanal, }(Z) \text {-3-hexene-1-ol, MeSA e nonanal +(Z)-3- } \\
\text { hexen-1-ol }\end{array}$ & DLC & $\begin{array}{l}\text { Os diferentes compostos atraíram predadores gener- } \\
\text { alistas de diferentes ordens taxonômicas. }\end{array}$ \\
\hline
\end{tabular}
hexen-1-ol

\begin{tabular}{llc}
\hline Milho $^{130}$ & $($ E)- $\beta$-cariofileno & $\begin{array}{c}\text { Plantas } \\
\text { transgênicas }\end{array}$ \\
\hline Uva, Milho, Brocoli $^{131}$ & $\begin{array}{l}\text { Antranilato de metila, benzaldeído, acetato de }(Z)-3- \\
\text { hexen-1-ila, MeSA e MeJA. }\end{array}$ & $\begin{array}{c}\text { Aplicação à } \\
\text { folhagem }\end{array}$
\end{tabular}

\begin{tabular}{lll}
\hline Morango $^{132}$ & MeSA & DLC
\end{tabular}

Milho ${ }^{116}$ Mistura de (Z)-3-hexenal, (Z)-3-hexenol, acetato de
(Z)-3-hexen-1-ila e $(E)$-2-hexenal

\section{DLC}

As plantas transgênicas atraíram nematoides entomopatogêneos que reduziram o dano por larvas de D. virgifera virgifera.

Os compostos avaliados atraíram insetos predadores, parasitoides da ordem Hymenoptera e thrips (Thysanoptera: Thripidae). MeSA e benzaldeído podem atrair os mesmos insetos em várias culturas. A concentração dos compostos afeta a atração de inimigos naturais.

O tratamento incrementou a abundância de inimigos naturais de vários grupos, mas não afetou a abundancia de pragas.

A mistura de VFVs induz a emissão de sesquiterpenos pelas plantas de milho, porém, não aumentou o parasitismo de lagartas.

\footnotetext{
${ }^{a}$ Estudos com outras culturas: nabo, ${ }^{113}$ lúpulo ${ }^{115}$ e cevada. ${ }^{120 ~ b}$ DLC $=$ Dispersores de Liberação Controlada.
} 
cis-jasmona) e é capaz de atrair inimigos naturais. Estudos de laboratório demonstraram que a indução de voláteis pelo ácido jasmônico atrai o ácaro predador $P$. persimilis em gérbera ${ }^{108} \mathrm{e}$ em feijão-de-lima. ${ }^{109} \mathrm{~A}$ resposta de vespas parasíticas generalistas e especialistas também foi avaliada. T. podisi, por exemplo, é atraída às plantas de soja tratadas com cis-jasmona, ${ }^{86} \mathrm{e}$ as vespas $C$. glomerata, C. rubecula e Diadegma semiclausum Hellen (Hymenoptera: Ichneumunidae) também são atraídas às plantas de couve tratadas com JA. ${ }^{110}$ Evidência das possibilidades do uso desses compostos em campo são baseados em testes realizados em algumas culturas (Tabela 1). A indução com ácido jasmônico beneficia as plantas através de uma combinação da indução de defesas diretas e indiretas nas plantas. ${ }^{111}$ Além dos derivados do ácido jasmônico, outros compostos podem afetar tanto pragas como inimigos naturais no campo. Em Nicotiana attenuatta Torr. ex S.Watson, o tratamento com MeJA, (Z)-3-hexene-1-ol, linalol e (Z)$\alpha$-bergamoteno incrementaram a mortalidade de ovos de Manduca sexta (Linnaeus, 1763) (Lepidoptera: Sphingidae) pelo percevejo predador Geocoris pallens Stål, 1954 (Hemiptera: Geocoridae). ${ }^{112}$ Além disso, a indução com linalool ou MeJA provocou a redução no índice de oviposição de $M$. sexta. ${ }^{112}$

\section{Armadilhas à base de compostos voláteis}

As versões sintéticas de muitos voláteis induzidos após o ataque dos herbívoros têm potencial para atrair inimigos naturais e promover o controle biológico em áreas agrícolas. Estudos realizados em campo utilizando dispersores de liberação controlada (Tabela 1) avaliaram um amplo número de compostos voláteis, incluindo, dentre outros compostos, derivados voláteis de hormônios, VFVs e terpenos. Em geral, o MeSA atrai um amplo espectro de inimigos naturais de diversas ordens e pode afetar a abundância de indivíduos de vários níveis tróficos. ${ }^{113}$ A diferença do MeSA, os terpenos e os VFVs são rapidamente degradados quando liberados na atmosfera. ${ }^{114}$ Isso explicaria a falta de atratividade dos inimigos naturais onde foram testados VFVs e (E)-DMNT. ${ }^{15,116}$ É possível que os compostos reativos sejam percebidos unicamente a uma curta distância pelos insetos. Entretanto, embora os VFVs induzam a emissão de sesquiterpenos, no campo não aumentam o parasitismo ${ }^{116}$ nem a atração de predadores do gênero Chrysopidae. ${ }^{117}$

Além de atrair inimigos naturais, os voláteis induzidos após o ataque dos herbívoros também podem ser utilizados na captura de insetos-praga. O MeSA já foi testado para este fim e teve resultados promissores. ${ }^{118}$ Por outro lado, esse composto pode inibir a oviposição e reduzir a incidência de pragas. Por exemplo, fêmeas acassaladas de Mamestra brassicae (Linnaeus, 1758) (Lepidoptera: Noctuidae) evitam plantas de Brassica napus com dispersores de $\mathrm{MeSA}^{119}$ e o estabelecimento do afídeo Rhopalosiphum padi (Linnaeus, 1758) (Hemiptera: Aphididae) é adiado em cevada quando MeSA é aplicado em pellets. ${ }^{120} \mathrm{O}$ uso de voláteis combinados com feromônios também pode ser uma alternativa para desenvolver atraentes mais eficientes de insetos-praga, uma vez que já foi observado o sinergismo entre estes semioquímicos. ${ }^{121}$

\section{Preparação das plantas a futuros ataques}

O fenômeno da preparação das plantas para futuros ataques pode ser induzido pela aplicação exógena de tratamentos químicos assim como pela exposição ao mesmo agente de stress, neste caso, a herbivoria. ${ }^{66}$ Apesar dos parâmetros na maioria dos estudos terem sido obtidos em laboratório, existem evidências da ocorrência deste fenômeno na natureza. De acordo com Merey e colaboradores, ${ }^{116}$ é possível que o uso de dispersores de liberação controlada induzam a liberação de voláteis por plantas vizinhas. Assim, esse fenômeno poderia ser usado para melhorar a resposta induzida das plantas à herbivoria, como um tipo de resistência.

\section{Desenvolvimento de plantas transgênicas}

A produção de plantas transgênicas que emitem maior quantidade de um ou vários voláteis induzidos pode favorecer a atração de inimigos naturais. Embora a maioria das avaliações sobre o efeito da transformação em inimigos naturais terem sido feitas em laboratório, ${ }^{76,122}$ existem evidências do seu potencial de implementação em campo em programas de manejo integrado de pragas. Degenhardt e colaboradores ${ }^{123}$ demonstraram que a incorporação do gene que codifica a síntese da molécula $(E)$ - $\beta$-cariofileno sintase, proveniente de orégano, a uma variedade americana de milho que não emite este composto, atraiu nematoides entomopatogênicos. $\mathrm{O}(E)$ - $\beta$-cariofileno está presente somente em variedades de milho européias e funciona como atraente a longa distância de nematoides entomopatogênicos, os quais exercem controle biológico sobre $D$. virgifera virgifera no ambiente subterrâneo. ${ }^{16} \mathrm{~A}$ modificação genética de plantas pode ser também dirigida para manipular o comportamento de insetos pragas. Por exemplo, plantas modificadas que expressam constitutivamente o feromônio de alerta de muitos afídeos, o composto (E)- $\beta$-farneseno, não só repele pulgões da espécie Myzus persicae (Sulzer, 1776) (Hemiptera: Aphididae), mas também atrai vespas parasitas como Diaeretiella rapae (M'Intosh, 1855) (Hymenoptera: Braconidae). ${ }^{124}$

\section{Incorporação na estratégia de "empurrar e puxar"}

A estratégia do "empurrar-puxar", baseada em sinais visuais e olfativos, envolve a manipulação do comportamento dos insetos-praga e de seus inimigos naturais através de uma integração de estímulos que atuam para manter o cultivo protegido ou inadequado para a praga (empurrar) e os atraiam a uma fonte (puxar), na qual são eliminados. ${ }^{125}$ Um caso bem sucedido foi demonstrado no Quênia, na África, onde voláteis de plantas nativas atraem e/ou repelem insetos-praga das plantações. Em plantações de milho, a planta Desmodium uncinatum repele insetos-praga que são subsequentemente atraídas para o capim-elefante-comum, que é plantada na borda da cultura. Essa estratégia é viável e eficiente no aumento da produtividade em pequenas propriedades. ${ }^{126}$ Como já mencionado, os voláteis induzidos por uma espécie herbívora podem exercer uma reação antagonista em co-específicos ou em indivíduos de outras especies evitando a oviposição de outros herbívoros. Por isso, poderiam ser incorporados à estratégia do "empurrar-puxar". Os elicitores, armadilhas e plantas transgênicas podem ser utilizados também nessa estratégia.

\section{PERSPECTIVAS DA UTILIZAÇÃO DE DEFESA INDUZIDA NO CONTROLE DE HERBÍVOROS}

A manipulação da emissão de voláteis em plantações pode ser uma excelente estratégia de controle de pragas, minimizando problemas com pragas agrícolas de uma maneira não-agressiva ao meio ambiente. No entanto, apesar das boas perspectivas, vários aspectos ainda precisam ser melhor explorados, garantindo a sustentabilidade do sistema de controle. Sobre o ponto de vista ecológico, o conhecimento das diferentes interações que mediam a emissão de voláteis é importante para explorar o uso de voláteis induzidos.

No contexto geral, é preciso entender como a defesa das plantas afeta a comunidade de insetos herbívoros, assim como a relação entre a produção de voláteis e a polinização. ${ }^{133}$ Também é necessário compreender se a indução da planta e o uso de compostos sintéticos têm algum efeito nos inimigos naturais e nos seus inimigos naturais (hiperparasitoides). ${ }^{113}$ Por exemplo, os jasmonatos incrementam a 
resistência a um amplo espetro de pragas e o parasitismo no campo, mas a indução das plantas pode afetar a eficiência dos parasitoides ao reduzir a qualidade do hospedeiro. ${ }^{111}$ Embora o fenômeno de indução reduz o custo destinado à manutenção das defesas, se conhece muito pouco sobre os custos metabólicos da planta ao ativar as defesas.

Do ponto de vista do controle de pragas, já se evidenciou o potencial de uso em campo das estratégias para atrair inimigos naturais, no entanto, elas não podem ser vistas como estratégias isoladas. $\mathrm{O}$ uso de elicitores de voláteis sintéticos é reconhecido como estratégia para prover o controle biológico. Esse uso implica na modificação do meio ambiente biótico, havendo a necessidade de fornecer fontes de alimento como néctar e pólen aos inimigos naturais, ${ }^{134}$ a fim de mantê-los sustentavelmente no campo, mesmo que o nível populacional dos herbívoros seja baixo.

Recentemente, tem se avaliado o efeito de diferentes concentrações de vários compostos voláteis aplicados diretamente em plantas de uva, milho e brócolis, com resultados promissores para o controle de pragas. ${ }^{131}$ Embora seja promissora, essa estratégia precisa de maiores estudos de campo. Por exemplo, devem ser estudados aspectos como a dinâmica populacional das pragas e dos inimigos naturais, assim como, avaliar o controle dos herbívoros, considerando-se que algumas pragas podem ser beneficiadas por determinados compostos. Além disso, é preciso determinar as dosagens, concentrações e o momento de aplicação, pois estes podem afetar a resposta dos inimigos naturais. ${ }^{110}$

Muitas considerações são necessárias antes de se implementar comercialmente dispersores de liberação controlada para o uso de compostos voláteis. Por exemplo, é necessário avaliar as taxas de emissão dos compostos, particularmente ao longo do ano, pela sua relação direta com a temperatura. ${ }^{117}$ Também deve ser considerada a longevidade dos compostos químicos no campo e a distância entre dispersores. Por outro lado, emissões homogêneas no campo podem reduzir a eficiência dos parasitoides a baixas densidades de praga. ${ }^{117}$ Porém, ainda é considerada uma alternativa para atrair inimigos naturais em períodos curtos. Da mesma forma que ocorre com os elicitores, é necessário avaliar o efeito nas dinâmicas populacionais dos herbívoros e inimigos naturais.

O conhecimento relacionado aos voláteis induzidos está limitado a poucos sistemas-modelo que incluem poucas espécies de plantas, seus herbívoros e inimigos naturais. Alguns grupos de pesquisa brasileiros já iniciaram estudos baseados em sistemas que incluem as culturas de soja ${ }^{86}$, milho ${ }^{58}$ e tomate. ${ }^{135}$ Em nosso laboratorio, pesquisas nesse campo têm sido iniciadas com espécies arbóreas de importância florestal, como o eucalipto (Eucalyptus benthamii Maiden \& Cambage) ${ }^{136}$ Porém, deve-se aprofundar ainda mais na identificação química de compostos que mediam interações multitróficas utilizando sistemas baseados em pragas e inimigos naturais que ocorrem no Brasil, considerando-se que este é um campo de pesquisa promisor que tem atraído cada vez mais grupos de pesquisa em todo o mundo.

\section{AGRADECIMENTOS}

Os autores agradecem ao Conselho Nacional de Desenvolvimento Científico e Tecnológico (CNPq) - Proc. No. 401928/2012-8, Coordenacão de Aperfeiçoamento de Pessoal de Nível Superior (CAPES) e Instituto Nacional de Ciências e Tecnologia (INCT) de Semioquímicos na Agricultura pelo apoio financeiro.

\section{REFERÊNCIAS}

1. Schoonhoven, L. M.; van Loon, J. J.; Dicke, M.; Insect-Plant Biology, $2^{\text {nd }}$ ed., Oxford University Press: Oxford, 2006.

2. Arimura, G.-I.; Kost, C.; Boland, W.; Biochim. Biophys. Acta 2005, $1734,91$.
3. Karban, R.; Baldwin, I. T.; Induced Responses to Herbivory, University of Chicago: Chicago, 1997.

4. Agrawal, A. A.; Karban, R. Em The Ecology and Evolution of Inducible Defenses; Tollrian, R.; Harvell, C. D., eds.; Princeton University Press: Princeton, 1999, cap. 3.

5. Agrawal, A. A.; Rutter, M. T.; Oikos 1998, 83, 227.

6. Turlings, T. C. J.; Wäckers, F. L. Em Advances in Insect Chemical Ecology; Cardé, R. T.; Millar, J., eds.; Cambridge University Press: Cambridge, 2004, cap. 2.

7. Pickett, J. A.; Bruce, T. J.; Chamberlain, K.; Hassanali, A.; Khan, Z. R.; Matthes, M. C.; Napier, J. A.; Smart, L. E.; Wadhams, L. J.; Woodcock, C. M. Em Chemical ecology: from gene to ecosystem; Dicke, M.; Takken, W., eds.; Springer: 2006, cap. 11.

8. Loreto, F.; Mannozzi, M.; Maris, C.; Nascetti, P.; Ferranti, F.; Pasqualini, S.; Plant Physiol. 2001, 126, 993.

9. Copolovici, L. O.; Filella, I.; Llusià, J.; Niinemets, U.; Peñuelas, J.; Plant Physiol. 2005, 139, 485.

10. Huang, M.; Sanchez-Moreiras, A. M.; Abel, C.; Sohrabi, R.; Lee, S.; Gershenzon, J.; Tholl, D.; New Phytol. 2012, 193, 997; Marei, G. I. K.; Abdel Rasoul, M. A.; Abdelgaleil, S. A. M.; Pestic. Biochem. Physiol. 2012, 103, 56.

11. McCallum, E. J.; Cunningham, J. P.; Lücker, J.; Zalucki, M. P.; De Voss, J. J.; Botella, J. R.; J. Exp. Biol. 2011, 214, 3672.

12. Raguso, R. A. Em Advances in Insect Chemical Ecology; Cardé, R. T.; Millar, J. G., eds.; Cambridge University Press: Cambridge, 2004, cap. 5

13. Pichersky, E.; Gershenzon, J.; Curr. Op. Plant Biol. 2002, 5, 237.

14. Bruce, T. J. A.; Wadhams, L. J.; Woodcock, C. M.; Trend. Plant Sci. 2005, 10, 269; Tooker, J. F.; Crumrin, A. L.; Hanks, L. M.; Chemoecology 2005, 15, 85.

15. Clavijo McCormick, A.; Unsicker, S. B.; Gershenzon, J.; Trend. Plant Sci. 2012, 17, 303.

16. Rasmann, S.; Kollner, T. G.; Degenhardt, J.; Hiltpold, I.; Toepfer, S.; Kuhlmann, U.; Gershenzon, J.; Turlings, T. C. J.; Nature 2005, 434, 732.

17. Arimura, G.; Shiojiri, K.; Karban, R.; Phytochemistry 2010, 71, 1642.

18. Tumlinson, J. H.; Turlings, T. C. J.; Lewis, W. J.; Agricult. Zool. Rev. 1992, 5, 221.

19. Dicke, M.; van Loon, J. J. A.; Entomol. Exp. Appl. 2000, 97, 237.

20. Smid, H. M.; van Loon, J. J. A.; Posthumus, M. A.; Vet, L. E. M.; Chemoecology 2002, 12, 169.

21. Shiojiri, K.; Takabayashi, J.; Yano, S.; Takafuji, A.; Appl. Entomol. Zool. 2000, 35, 87.

22. Tamiru, A.; Bruce, T. J. A.; Woodcock, C. M.; Caulfield, J. C.; Midega, C. A. O.; Ogol, C. K. P. O.; Mayon, P.; Birkett, M. A.; Pickett, J. A.; Khan, Z. R.; Ecol. Lett. 2011, 14, 1075.

23. Boff, M.; Wiegers, G.; Smits, P.; Biocontrol Sci. Technol. 2001, 11, 493.

24. van Den Boom, C. E. M.; van Beek, T. A.; Posthumus, M. A.; De Groot, A.; Dicke, M.; J. Chem. Ecol. 2004, 30, 69.

25. De Moraes, C. M.; Lewis, W. J.; Paré, P. W.; Alborn, H. T.; Tumlinson, J. H.; Nature 1998, 393, 570.

26. Yoneya, K.; Kugimiya, S.; Takabayashi, J.; Physiol. Entomol. 2009, 34, 379.

27. Kappers, I. F.; Hoogerbrugge, H.; Bouwmeester, H. J.; Dicke, M.; J. Chem. Ecol. 2011, 37, 150.

28. Rostás, M.; Eggert, K.; Chemoecology 2008, 18, 29.

29. Arimura, G.; Köpke, S.; Kunert, M.; Volpe, V.; David, A.; Brand, P.; Dabrowska, P.; Maffei, M. E.; Boland, W.; Plant Physiol. 2008, 146, 965.

30. De Moraes, C. M.; Mescher, M. C.; Tumlinson, J. H.; Nature 2001, 410, 577

31. Gouinguené, S. P.; Turlings, T. C. J.; Plant Physiol. 2002, 129, 1296.

32. Gouinguené, S.; Alborn, H.; Turlings, T. C. J.; J. Chem. Ecol. 2003, 29, 145 . 
33. Dicke, M. Em The Ecology and Evolution of Inducible Defenses; Tollrian, R.; Harvell, C. D., eds.; Princeton University Press: New Jersey, 1999, cap. 4.

34. Fritzsche Hoballah, M. E.; Tamo, C.; Turlings, T. C. J.; J. Chem. Ecol. 2002, 28, 951

35. De Boer, J. G.; Dicke, M.; Appl. Entomol. Zool. 2005, 40, 1.

36. Dudareva, N.; Negre, F.; Nagegowda, D. A.; Orlova, I.; Crit. Rev. Plant Sci. 2006, 25, 417.

37. Baldwin, I. T.; Schultz, J. C.; Science 1983, 221, 277.

38. Fowler, S. V.; Lawton, J. H.; Am. Nat. 1985, 162, 181; Dicke, M.; Bruin, J.; Biochem. Syst. Ecol. 2001, 29, 981.

39. Bate, N. J.; Rothstein, S. J.; Plant J. 1998, 16, 561.

40. Engelberth, J.; Seidl-Adams, I.; Schultz, J. C.; Tumlinson, J. H.; Molecular Plant Microbe Interactions 2007, 20, 707

41. Arimura, G.; Ozawa, R.; Shimoda, T.; Nishioka, T.; Boland, W.; Takabayashi, J.; Nature 2000, 406, 512.

42. Ton, J.; D’Alessandro, M.; Jourdie, V.; Jakab, G.; Karlen, D.; Held, M.; Mauch-Mani, B.; Turlings, T. C. J.; Plant J. 2006, 49, 16.

43. Kost, C.; Heil, M.; J. Ecol. 2006, 94, 619.

44. Choh, Y.; Kugimiya, S.; Takabayashi, J.; Oecologia 2006, 147, 455.

45. Dicke, M.; Agrawal, A. A.; Bruin, J.; Trends Plant Sci. 2003, 8, 403.

46. Choh, Y.; Shimoda, T.; Ozawa, R.; Dicke, M.; Takabayashi, J.; J. Chem. Ecol. 2004, 30, 1305.

47. Mirabella, R.; Rauwerda, H.; Struys, E. A.; Jakobs, C.; Triantaphylidès, C.; Haring, M. A.; Schuurink, R. C.; Plant J. 2008, 53, 197.

48. Ruther, J.; Kleier, S.; J. Chem. Ecol. 2005, 31, 2217.

49. Frost, C. J.; Mescher, M. C.; Dervinis, C.; Davis, J. M.; Carlson, J. E.; De Moraes, C. M.; New Phytol. 2008, 180, 722.

50. Godard, K. A.; White, R.; Bohlmann, J.; Phytochemistry 2008, 69, 1838.

51. Karban, R.; Maron, J.; Ecology 2002, 83, 1209.

52. Shulaev, V.; Silverman, P.; Raskin, I.; Nature 1997, 385, 718.

53. O’Donnell, P.; Calvert, C.; Atzorn, R.; Wasternack, C.; Leyser, H.; Bowles, D.; Science 1996, 274, 1914.

54. Bernasconi, M. L.; Turlings, T. C. J.; Ambrosetti, L.; Bassetti, P.; Dorn, S.; Entomol. Exp. Appl. 1998, 87, 133.

55. Bolter, C. J.; Dicke, M.; van Loon, J. J. A.; Visser, J.; Posthumus, M. A.; J. Chem. Ecol. 1997, 23, 1003.

56. Lucas-Barbosa, D.; van Loon, J. J. A.; Dicke, M.; Phytochemistry 2011, $72,1647$.

57. Fatouros, N. E.; Lucas-Barbosa, D.; Weldegergis, B. T.; Pashalidou, F. G.; van Loon, J. J. A.; Dicke, M.; Harvey, J. A.; Gols, R.; Huigens, M. E.; PLoS one 2012, 7, e43607.

58. Peñaflor, M. F. G. V.; Erb, M.; Robert, C. A. M.; Miranda, L. A.; Werneburg, A. G.; Dossi, F. C. A.; Turlings, T. C. J.; Bento, J. M. S.; Planta 2011, 234, 207.

59. Bruce, T. J. A.; Midega, C. A. O.; Birkett, M. A.; Pickett, J. A.; Khan, Z. R.; Biol. Lett. 2010, 6, 314.

60. Holopainen, J. K.; Trend. Plant Sci. 2004, 9, 529.

61. Matsui, K.; Curr. Op. Plant Biol. 2006, 9, 274.

62. Rose, U. S. R.; Manukian, A.; Heath, R. R.; Tumlinson, J. H.; Plant Physiol. 1996, 111, 487.

63. Turlings, T. C. J.; McCall, P. J.; Alborn, H. T.; Tumlinson, J. H.; J. Chem. Ecol. 1993, 19, 411.

64. D’Auria, J. C.; Pichersky, E.; Schaub, A.; Hansel, A.; Gershenzon, J.; Plant J. 2007, 49, 194.

65. Arimura, G.; Matsui, K.; Takabayashi, J.; Plant Cell Physiol. 2009, 50, 911.

66. Turlings, T. C. J.; Ton, J.; Curr. Op. Plant Biol. 2006, 9, 421.

67. Paré, P. W.; Tumlinson, J. H.; Plant Physiol. 1997, 114, 1161.

68. Bartram, S.; Jux, A.; Gleixner, G.; Boland, W.; Phytochemistry 2006, 67, 1661; Arimura, G.; Garms, S.; Maffei, M.; Bossi, S.; Schulze, B.; Leitner, M.; Mithöfer, A.; Boland, W.; Planta 2008, 227, 453.

69. Tholl, D.; Sohrabi, R.; Huh, J. H.; Lee, S.; Phytochemistry 2011, 72, 1635.
70. Arimura, G.; Garms, S.; Maffei, M.; Bossi, S.; Schulze, B.; Leitner, M.; Mithöfer, A.; Boland, W.; Planta 2008, 227, 453.

71. Lee, H. I.; León, J.; Raskin, I.; Proc. Natl. Acad. Sci. U.S.A. 1995, 92 , 4076.

72. van Poecke, R. M. P.; Dicke, M.; J. Exp. Botany 2002, 53, 1793.

73. Mattiacci, L.; Dicke, M.; Posshumus, M. A.; Proc. Natl. Acad. Sci. U.S.A. 1995, 92, 2036; Alborn, H. T.; Turlings, T. C. J.; Jones, T. H.; Stenhagen, G.; Loughrin, J. H.; Tumilson, J. H.; Science 1997, 276, 945.

74. Wu, J.; Baldwin, I. T.; Plant Cell Environ. 2009, 32, 1161.

75. Mithöfer, A.; Wanner, G.; Boland, W.; Plant Physiol. 2005, 137, 1160.

76. Schnee, C.; Köllner, T. G.; Held, M.; Turlings, T. C. J.; Gershenzon, J.; Degenhardt, J.; Proc. Natl. Acad. Sci. U.S.A. 2006, 103, 1129.

77. Ballaré, C. L.; Trend. Plant Sci. 2011, 16, 249.

78. Reymond, P.; Farmer, E. E.; Curr. Op. Plant Biol. 1998, 1, 404.

79. Maffei, M. E.; Arimura, G. I.; Mithöfer, A.; Nat. Prod. Rep. 2012, 29 , 1288

80. Kessler, A.; Baldwin, I. T.; Annu. Rev. Plant Biol. 2002, 53, 299

81. Alborn, H. T.; Hansen, T. V.; Jones, T. H.; Bennett, D. C.; Tumlinson, J. H.; Schmelz, E. A.; Teal, P. E. A.; Proc. Natl. Acad. Sci. U.S.A. 2007, 104, 12976.

82. Ma, R.; Chen, J. L.; Cheng, D. F.; Sun, J. R.; J. Agr. Food Chem. 2010 , 58,2410

83. Felton, G. W.; Tumlinson, J. H.; Curr. Op. Plant Biol. 2008, 11, 457.

84. Rodríguez-Saona, C.; Crafts-Brandner, S. J.; Williams, L.; Pare, P. W.; J. Chem. Ecol. 2002, 28, 1733.

85. Hilker, M.; Meiners, T.; Biol. Rev. 2010, 85, 267.

86. Moraes, M. C. B.; Laumann, R. A.; Pareja, M.; Sereno, F. T. P. S.; Michereff, M. F. F.; Birkett, M. A.; Pickett, J. A.; Borges, M.; Entomol. Exp. Appl. 2009, 131, 178.

87. Farmer, E. E.; Ryan, C. A.; Proc. Nat. Acad. Sci. U.S.A. 1990, 87, 7713.

88. Gundlach, H.; Müller, M. J.; Kutchan, T. M.; Zenk, M. H.; Proc. Natl. Acad. Sci. U.S.A. 1992, 89, 2389.

89. Gardner, H. W.; HortScience 1995, 30, 186.

90. Walling, L. L.; J. Plant Growth Regul. 2000, 19, 195.

91. Zarate, S. I.; Kempema, L. A.; Walling, L. L.; Plant Physiol. 2007, 143, 866.

92. Dempsey, D. M. A.; Shah, J.; Klessig, D. F.; Crit. Rev. Plant Sci. 1999 , $18,547$.

93. Ament, K.; Kant, M. R.; Sabelis, M. W.; Haring, M. A.; Schuurink, R. C.; Plant Physiol. 2004, 135, 2025.

94. Ozawa, R.; Arimura, G.; Takabayashi, J.; Shimoda, T.; Nishioka, T.; Plant Cell Physiol. 2000, 41, 391.

95. Penninckx, I. A. M. A.; Thomma, B. P. H. J.; Buchala, A.; Métraux, J. P.; Broekaert, W. F.; Plant Cell 1998, 10, 2103.

96. Watanabe, M.; Moraes, G. J.; Gastaldo Jr, I.; Nicolella, G.; Sci. Agric. 1994, 51, 75.

97. Hilker, M.; Stein, C.; Schröder, R.; Varama, M.; Mumm, R.; J. Exp. Biol. 2005, 208, 1849.

98. Tooker, J. F.; De Moraes, C. M.; J. Chem. Ecol. 2007, 33, 331.

99. Koornneef, A.; Pieterse, C. M. J.; Plant Physiol. 2008, 146, 839.

100. Bruessow, F.; Gouhier-Darimont, C.; Buchala, A.; Metraux, J. P.; Reymond, P.; Plant J. 2010, 62, 876.

101. Rasmann, S.; Turlings, T. C. J.; Ecol. Lett. 2007, 10, 926.

102. Soler, R.; Harvey, J. A.; Kamp, A. F. D.; Vet, L. E. M.; van der Putten, W. H.; van Dam, N. M.; Stuefer, J. F.; Gols, R.; Hordijk, C. A.; Martijn Bezemer, T.; Oikos 2007, 116, 367.

103. Zhang, P. J.; Zheng, S. J.; van Loon, J. J. A.; Boland, W.; David, A.; Mumm, R.; Dicke, M.; Proc. Natl. Acad. Sci. U.S.A. 2009, 106, 21202.

104. Zarbin, P. H. G.; Rodrigues, M. A. C. M.; Lima, E. R.; Quim. Nova 2009, 32, 722.

105. Shrivastava, G.; Rogers, M.; Wszelaki, A.; Panthee, D. R.; Chen, F.; Crit. Rev. Plant Sci. 2010, 29, 123.

106. Hunter, M. D.; Agr. Forest Entomol. 2002, 4, 81 
107. Stout, M. J.; Zehnder, G. W.; Baur, M. E.; Arch. Insect Biochem. Physiol. 2002, 51, 222.

108. Gols, R.; Posthumus, M.; Dicke, M.; Entomol. Exp. Appl. 1999, 93, 77.

109. Dicke, M.; Gols, R.; Ludeking, D.; Posthumus, M. A.; J. Chem. Ecol. 1999, 25, 1907.

110. Bruinsma, M.; Posthumus, M. A.; Mumm, R.; Mueller, M. J.; van Loon, J. J. A.; Dicke, M.; J. Exp. Bot. 2009, 60, 2575.

111. Thaler, J. S.; Nature 1999, 399, 686; Thaler, J. S.; J. Anim. Ecol. 2002, $71,141$.

112. Kessler, A.; Baldwin, I. T.; Science 2001, 291, 2141.

113. Orre, G.; Wratten, S.; Jonsson, M.; Hale, R.; Biol. Control 2010, 53, 62.

114. Pinto, D. M.; Blande, J. D.; Nykänen, R.; Dong, W.-X.; Nerg, A.-M.; Holopainen, J. K.; J. Chem. Ecol. 2007, 33, 683.

115. James, D. G.; Environ. Entomol. 2003, 32, 977.

116. Mérey, G.; Veyrat, N.; Mahuku, G.; Valdez, R. L.; Turlings, T. C. J.; D’Alessandro, M.; Phytochemistry 2011, 72, 1838.

117. Jones, V. P.; Steffan, S. A.; Wiman, N. G.; Horton, D. R.; Miliczky, E.; Zhang, Q. H.; Baker, C. C.; Biol. Control 2011, 56, 98.

118. Bengtsson, M.; Jaastad, G.; Knudsen, G.; Kobro, S.; Bäckman, A. C.; Pettersson, E.; Witzgall, P.; Entomol. Exp. Appl. 2006, 118, 77.

119. Ulland, S.; Ian, E.; Stranden, M.; Borg-Karlson, A. K.; Mustaparta, H.; Chem. Senses 2008, 33, 509.

120. Ninkovic, V.; Ahmed, E.; Glinwood, R.; Pettersson, J.; Agr. Forest Entomol. 2003, 5, 27.

121. Reddy, G. V. P.; Guerrero, A.; Trend. Plant Sci. 2004, 9, 253.

122. Kappers, I. F.; Aharoni, A.; Van Herpen, T. W. J. M.; Luckerhoff, L. L. P.; Dicke, M.; Bouwmeester, H. J.; Sci. Signal. 2005, 309, 2070.

123. Degenhardt, J.; Gershenzon, J.; Baldwin, I. T.; Kessler, A.; Curr. Op. Biotech. 2003, 14, 169.
124. Beale, M. H.; Birkett, M. A.; Bruce, T. J. A.; Chamberlain, K.; Field, L. M.; Huttly, A. K.; Martin, J. L.; Parker, R.; Phillips, A. L.; Pickett, J. A.; Prosser, I. M.; Shewry, P. R.; Smart, L. E.; Wadhams, L. J.; Woodcock, C. M.; Zhang, Y.; Proc. Natl. Acad. Sci. U.S.A. 2006, 103, 10509.

125. Cook, S. M.; Khan, Z. R.; Pickett, J. A.; Annu. Rev. Entomol. 2007, 52, 375.

126. Khan, Z. R.; Midega, C. A. O.; Amudavi, D. M.; Hassanali, A.; Pickett, J. A.; Field Crop. Res. 2008, 106, 224.

127. James, D. G.; Price, T. S.; J. Chem. Ecol. 2004, 30, 1613; James, D. G.; Grasswitz, T. R.; BioControl 2005, 50, 871.

128. Zhu, J.; Park, K.-C.; J. Chem. Ecol. 2005, 31, 1733; Mallinger, R. E.; Hogg, D. B.; Gratton, C.; J. Econ. Entomol. 2011, 104, 115.

129. Yu, H.; Zhang, Y.; Wu, K.; Gao, X. W.; Guo, Y. Y.; Environ. Entomol. 2008, 37, 1410 .

130. Degenhardt, J.; Hiltpold, I.; Köllner, T. G.; Frey, M.; Gierl, A.; Gershenzon, J.; Hibbard, B. E.; Ellersieck, M. R.; Turlings, T. C. J.; Proc. Natl. Acad. Sci. U.S.A. 2009, 106, 13213.

131. Simpson, M.; Gurr, G. M.; Simmons, A. T.; Wratten, S. D.; James, D. G.; Leeson, G.; Nicol, H. I.; Agr. Forest Entomol. 2011, 13, 45.

132. Lee, J. C.; Environ. Entomol. 2010, 39, 653.

133. Bruinsma, M.; IJdema, H.; Van Loon, J. J. A.; Dicke, M.; Entomol. Exp. Appl. 2008, 128, 109; Kessler, D.; Diezel, C.; Baldwin, I. T.; Curr. Biol. 2010, 20, 237.

134. Wäckers, F. L.; Romeis, J.; van Rijn, P.; Annu. Rev. Entomol. 2007, 52, 301.

135. Sarmento, R. D. E. A.; Tese de Doutorado, Universidade Federal de Viçosa, Viçosa, Brasil, 2007.

136. Martins, C. B. C.; Zarbin, P. H. G.; J. Chem. Ecol. 2013, 39, 602. 